\title{
Influence of Pos Giro Mobile (PGM) in Running the Service Process of PT. Pos Indonesia (Case Study at Padangsidimpuan Post Office)
}

\section{Pengaruh Pos Giro Mobile (PGM) dalam Menjalankan Proses Pelayanan PT. Pos Indonesia (Studi Kasus Pada Kantor Pos Padangsidimpuan)}

\author{
Ayu Widyastuti Rafisa'); Halimah Safitry Al-Fauziah'2); Nurbaiti²) \\ 1,2)Study Program of Management Faculty of Economic, Universitas Islam Negeri Sumatera Utara \\ Email: ${ }^{1)}$ ayuwidyastuti775@gmail.com ${ }^{2)}$ safitry13112001@gmail.com ${ }^{3)}$ Nurbaiti@uinsu.ac.id
}

\section{How to Cite :}

Rafisa, A. W., Al-Fauziah, H. S., Nurbaiti. (2022). Influence of Pos Giro Mobile (PGM) in Running the Service Process of PT. Pos Indonesia (Case Study at Padangsidimpuan Post Office). Jurnal Ekonomi Manajemen Akuntansi Dan Keuangan, 3(1). DOI: https://doi.org/10.53697/emak.v3i1

ARTICLE HISTORY

Received [1 Desember 2021]

Revised [10 Desember 2021]

Accepted [28 Desember 2021]

\section{KEYWORDS}

E-Business; Pos Giro Mobile; technology, digital; service

This is an open access article under the $C C-B Y$-SA license

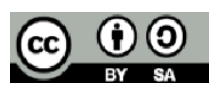

\begin{abstract}
ABSTRAK
Seiring pesatnya perkembangan teknologi, pebisnis dituntut untuk dapat memanfaatkan internet sebagai media melakukan bisnis secara online guna untuk meningkatkan efektivitas pelayanan agar pelanggan dapat mengakses layanan dengan mudah dimana saja dan kapan saja. Penelitian ini bertujuan untuk menganalisis bagaimana peran Pos Giro Mobile (PGM) dalam menjalankan proses pelayanan PT. Pos Indonesia. Metode penelitian yang digunakan bersifat deskriptif dengan meneliti apa saja manfaat dan bagaimana upaya mengenalkan PGM pada masyarakat serta hambatan apa saja yang dilalui. Hasil penelitian menunjukkan bahwa PT. Pos Indonesia telah mengenalkan produk Pos Giro Mobile (PGM) pada masyarakat. Namun masyarakat yang minim pengetahuan terhadap teknologi menjadi salah satu hambatan sehingga PT. Pos Indonesia memutuskan untuk sosialisasi secara langsung sekaligus mengajarkan bagaimana cara menggunakan aplikasi tersebut.
\end{abstract}

\section{ABSTRACT}

Along with the rapid development of technology, business people are required to be able to use the internet as a medium for doing business online in order to increase service effectiveness so that customers can access services easily anywhere and anytime. This study aims to analyze how the role of Pos Giro Mobile (PGM) in carrying out the service process of $P T$. Indonesian post. The research method used is descriptive by examining what are the benefits and how to introduce PGM to the community as well as what obstacles are passed. The results showed that PT. Pos Indonesia has introduced the Pos Giro Mobile (PGM) product to the public. However, people who lack knowledge of technology become one of the obstacles so that PT. Pos Indonesia decided to socialize directly as well as teach how to use the application.

\section{PENDAHULUAN}

Di era modern ini, persaingan bisnis menjadi sangat ketat karena media digitaldapat dengan mudah diakses dan dapat digunakan oleh banyak orang, dan media digital telah banyak membantu segala rutinitas banyak orang, mulai dari kegiatan komunikasi hingga penyebaran informasi dapat diterima dengan cepat. Saat ini fenomena penciptaan teknologi oleh semua perusahaan besar di era globalisasi ini semakin mengetat, agar selalu berkembang dan menguasai pangsa pasar (market 
share). Merek dan brand merupakan komponen yang sangat penting dalam memudahkan konsumen untuk mengingat suatu produk dan juga sebagai ciri pembeda aplikasi atau produk tersebut dari para pesaingnya.

Pada pasar e-business, para pendatang baru mempunyai keunggulan yang signifikan dibandingkan usaha yang telah ada. Pada dasarnya, perusahaan lebih mengandalkan formula sederhana dimana biaya operasional diusahakan harus rendah, produksi meningkat, dan membuka cabang baru dengan begitu mereka menjadi jarang berinovasi di pasar. Sifat pendatang baru tidaklah demikian dalam mengidentifikasi nilai-nilai yang baru bagi perusahaan. Karena itu, perusahaan yang telah lama berkecimpung dalam bisnis perlu memikirkan kembali pemikiran mereka dan melakukan perubahan mendasar. Manajemen harus mampu menjaga tingkat kenyamanan yang baik agar tidak terjadi yang namanya status quo, yaitu pengembangan kemampuan untuk memperhatikan trend yang tengah terjadi terlebih dahulu untuk mengantisipasi persaingan, mengambil keputusan yang cepat dan tangkas untuk membentuk atau mengadopsi model bisnis yang baru.

Pesatnya perkembangan yang seolah tidak ada habisnya di bidang Teknologi Informasi (TI) yang secara langsung juga mendukung terhadap perkembangan internet, semakin memudahkan para pengguna (users) dalam hal ini para pengusaha untuk mengelola dan dengan mudah mengembangkan usaha dan kegiatan bisnis. Kelajuan dunia Internet membuat kemunngkinan adanya berbagai teknologi yang membantu dalam hal mempublikasikan informasi yang beragam dalam format elektronik, tidak hanya dengan cara yang efisien dan ramah terhadap pengguna (user friendly), namun juga dengan cara menawarkan mekanisme guna untuk menyediakan basis data terpusat serta sistem navigasi umum yang dapat digunakan oleh siapapun dengan cara yang tidak terlalu sulit.

E-Business adalah penggunaan teknologi informasi untuk memfasilitasi guna mempermudah dalam proses bisnis, melakukan e-commerce dan memberikan dukungan kerjasama dan komunikasi dengan perusahaan pendukung menurut Abdurrozak et.al (2020). Selain itu, E-Business juga dapat didefenisikan sebagai suatu kegiatan yang secara langsung atau tidak langsung terlibat dalam proses pertukaran barang atau jasa dengan menggunakan media sebagai alat komunikasi. Business merupakan implementasi dan pengelolaan serangkaian proses bisnis utama seperti desain produk, manajemen pasokan bahan baku, produksi, penjualan, memenuhi pesanan, dan menyediakan layanan melalui pemanfaaan teknologi komunikasi komputer dan data yang telah terkomputerisasi oleh Sairamesh (2004). E-business memanfaatkan teknologi informasi berupa internet dan jaringan komputer lainnya untuk melakukan proses bisnis utama yakni penjualan dan pembelian. Awalan "e" pada kata e-business memiliki arti "elektronik" yang bermakna kegiatan atau transaksi yang digunakan tanpa pertukaran atau kontak fisik, transaksi dilaksanakan secara elektronik atau digital, hal ini jadi memungkinkan dengan dukungan perkembangan komunikasi digital yang terbilang pesat.

PT. Pos Indonesia merupakan perusahaan Badan Usaha Milik Negara (BUMN) yang berkiprah pada bidang jasa kurir, logistik, dan transaksi keuangan. PT Pos Indonesia memberikan kemudahan akses layanan transaksi keuangan bagi pelanggan pos dengan menyediakan layanan mobile yang dapat diakses kapan saja, di mana saja untuk memenuhi perkembangan teknologi informasi dan kebutuhan masyarakat (khususnya pelanggan pos) serta upaya untuk dengan mudah mendukung strategi nasional untuk meningkatkan akses layanan dan inklusi keuangan di Indonesia kapan saja, di mana saja. Pos Giro Mobile (PGM) adalah sebuah layanan Teknik Informatika yang bersifat platform digital berbasis rekening Giropos yang digunakan oleh pelanggan Pos Indonesia yang dapat mengakses layanan Giropos dan layanan transaksi keuangan pos lainnya secara mobile. Pos Giro Mobile merupakan layanan yang lebih fleksibelyang dapat diintegrasikan dengan bank, merchant dan pihak yang lain, sehingga dengan satu rekening pos Giro, anda bisa melakukan banyak hal seperti transfer, pembayaran bahkan bisa juga untuk melakukan pembelian di Indomaret dengan menggunakan rekening tersebut. 
Pos Giro Mobile adalah jawaban atas pesatnya kebutuhan masyarakat yang saat ini terasa serba cepat dikatakan oleh Ihwan Sutardiyanta. Kantor Pos menawarkan kemudahan pelayanan dan fasilitas pelayanan transaksi keuangan secara mobile, yang mudah diakses kapan saja dan dimana saja. Pelanggan juga dapat menggunakan virtual account untuk membayar uang sekolah dan lainlain. Layanan Giropos merupakan salah satu layanan keuangan legacy selain Weselpos yang dimiliki oleh PT. Pos Indonesia (Persero) dan juga layanan Giropos juga digunakan untuk mendukung program-program pemerintah dalam hal penyaluran dana ke berbagai wilayah di Indonesia. Untuk itu, Pos Indonesia meluncurkan aplikasi yang dapat membantu masyarakat umum melakukan pembayaran apapun melalui Pos Giro Mobile. Seiring perkembangan zaman, sebagian masyarakat pelan tapi pasti telah meninggalkan era pembayaran tunai. Data Bank Indonesia (BI) menunjukkan nilai transaksi uang elektronik pada bulan November 2021 telah tercatat sebesar Rp. 31,3 Triliun atau tumbuh $61,82 \%$ year of year dan nilai transaksi digital banking meningkat dari $47,08 \%$ year of year menjadi Rp. 3.877,3 triliun. Hal ini menunjukkan bahwa pembayaran secara online atau online payment menjadi pilihan masyarakat karena memiliki beberapa keunggulan. Yang utamanya karena lebih praktis, pembayaran bisa dilakukan dimana saja dan kapan saja.

Perumusan masalah dalam penelitian ini adalah: (1) Bagaimana penerapan e-business pada Pos Giro Mobile? (2) Apa saja hambatan-hambatan dalam memperkenalkan Pos Giro Mobile ini dikalangan masyarakat Kota Padangsidimpuan? (3) Bagaimana upaya dalam mengatasi hambatan tersebut? (4) Apakah PGM dapat membantu mempermudah masyarakat tersebut dalam menggunakan pelayanan PT. Pos Indonesia? Hal tersebut dalam rangka (1) Untuk mengetahui penerapan e-business pada Pos Giro Mobile. (2) Untuk mengetahui hambatan-hambatan dalam memperkenalkan Pos Giro Mobile ini dikalangan masyarakat Kota Padangsidimpuan. (3) Untuk mengetahui upaya dalam mengatasi hambatan tersebut. (4) Untuk mengetahui bagaimana PGM dapat membantu mempermudah masyarakat tersebut dalam menggunakan pelayanan PT. Pos Indonesia. Penelitian yang dilakukan terhadap Kantor Pos Padangsidimpuan ditemukan bahwa (1) PT. Pos Indonesia memanfaatkan teknologi dalam Pos Giro Mobile. (2) Masyarakat masih minim pengetahuan terhadap teknologi. (3) PT. Pos Indonesia melakukan sosialisasi bertujuan untuk mengajarkan penggunaan PGM secara langsung. (4) PGM menyediakan fitur yang telah bekerja sama dengan beberapa bank sehingga dapat dimanfaatkan untuk transaksi lainnya.

\section{LANDASAN TEORI}

\section{Pengertian E-Business}

Abdurrozzak Hasibuan dkk (2020). E-Business adalah penggunaan teknologi informasi untuk memfasilitasi guna mempermudah dalam proses bisnis, melakukan e-commerce dan memberikan dukunngan kerjasama dan komunikasi dengan perusahaan pendukung. Selain itu, E-Business juga dapat didefenisikan sebagai suatu kegiatan yang secara langsung atau tidak langsung terlibat dalam proses pertukaran barang atau jasa dengan menggunakan media sebagai alat komunikasi.

Sairamesh (2004) E-Business merupakan implementasi dan pengelolaan serangkaian proses bisnis utama seperti desain produk, manajemen pasokan bahan baku, produksi, penjualan, memenuhi pesanan, dan menyediakan layanan melalui pemanfaaan teknologi komunikasi komputer dan data yang telah terkomputerisasi. E-business memanfaatkan teknologi informasi berupa internet dan jaringan komputer lainnya untuk melakukan proses bisnis utama yakni penjualan dan pembelian. Awalan "e" pada kata e-business memiliki arti "elektronik" yang bermakna kegiatan atau transaksi yang digunakan tanpa pertukaran atau kontak fisik, transaksi dilaksanakan secara elektronik atau digital, hal ini jadi memungkinkan dengan dukungan perkembangan komunikasi digital yang terbilang pesat.

\section{Pengertian Pos Giro Mobile (PGM)}

Pos Giro Mobile, adalah aplikasi Smartphone berbasis Android yang tersedia bagi pelanggan sebagai kanal digital untuk mengakses layanan pos Giro dan layanan transaksi keuangan lainnya secara mandiri. Pos Giro Mobile merupakan layanan yang lebih fleksibel yang dapat 
diintegrasikan dengan bank, merchant dan pihak yang lain, sehingga dengan satu rekening pos Giro, anda bisa melakukan banyak hal seperti transfer, pembayaran bahkan bisa juga untuk melakukan pembelian di Indomaret dengan menggunakan rekening tersebut.

Ihwan Sutardiyanta mengatakan bahwasanya Pos Giro Mobile adalah jawaban atas pesatnya kebutuhan masyarakat yang saat ini terasa serba cepat. Kantor Pos menawarkan kemudahan pelayanan dan fasilitas pelayanan transaksi keuangan secara mobile, yang mudah diakses kapan saja dan dimana saja. Pelanggan juga dapat menggunakan virtual account untuk membayar uang sekolah dan lain-lain.

\section{METODE PENELITIAN}

\section{Metode Analisis}

Metode yang digunakan dalam penelitian ini adalah berdasarkan penelitian deskriptif kualitatif yaitu dengan meneliti langsung melalui wawancara kemudian menganalisis informasi yang didapatkan, selain itu dalam penelitian ini juga bersumber dari jurnal-jurnal terdahulu yang berkaitan dengan judul yang diteliti. Pembahasan tentang teori sejarah ebusiness diperoleh dari beberapa macam buku dan jurnal ilmiah yang banyak membahas tentang e-business.

\section{HASIL DAN PEMBAHASAN}

Istilah e-business ini diperkenalkan pertama kali oleh Louis Gerstner, seorang CEO di perusahaan IBM. Menurut IBM sendiri, e-business merupakan sebuah pendekatan yang aman, fleksible serta terintegrasi guna memberikan nilai bisnis yang beragam dengan menggabungkan sistem dan proses yang mengelola operasi bisnis terpenting dengan menggunakan pemanfaatan teknologi internet. Setelah konsep e-business ini dipopulerkan oleh IBM, banyak perusahaan perangkat lunak besar muncul dan berpartisipasi dalam pengembangan layanan e-business. Konsep e-business ini di motivasi oleh adanya krisis yang dialami oleh IBM dimana pada akhirnya mereka mengganti CEO-nya pada tahun 1991 karena pertumbuhan internet sangat cepat pada tahun itu. Melihat keadaan tersebut yang dapat mengubah cara kerja perusahaan, akhirnya pada tahun 1995 Louis Gerstner selaku penerus CEO yang menggantikannya, berhasil menghadapi krisis tersebut dan memperkenalkan bagaimana internet dapat menjadi salah satu alat bisnis-ke-bisnis yang sangat bermanfaat.

Untuk mewujudkan rencana besar Louis, divisi internet akhirnya dibentuk dibawah kepemimpinan Irving Wladawsky Berger, yang bertugas untuk merumuskan dan menjalankan strategi internet perusahaan untuk keseluruhan unit bisnis. Dengan begitu, pada saat musim gugur tahun 1997 melalui IBM Louis mengkampanyekan pemasaran yang sangat kreatif guna untuk mengajak dan menyediakan pelayanan sehingga setiap perusahaan dapat menerapkan e-business serta memanfaatkan internet sebagai salah satu nilai bisnis.

Sejarah telah lama mendokumentasikan keberadaan Pos Indonesia, kantor pos pertama didirikan di Batavia (sekarang Jakarta) oleh Gubernur Jenderal G.W Baron Van Imhoff saat tanggal 26 Agustus 1746 yang bertujuan memberikan keamanan yang terjamin terhadap dokumen penting penduduk utamanya untuk mereka yang berjualan dari kantor-kantor di luar Jawa serta untuk mereka yang datang dan pergi ke Negeri Belanda. Sejak saat itu, lahirlah pelayanan pos untuk mengemban peran dan fungsi pelayanan terhadap public. Sesudah berdirinya kantor pos Batavia, terhitung empat tahun kemudian Kantor pos Semarang didirikan guna melaksanakan komunikasi pos yang teratur antara kedua tempat ini dan mempercepat pengiriman jalur perjalanan pos kala itu melalui Karawang, Cirebon, Pekalongan. Pos Indonesia telah beberapa kali melalui pergantian status mulai dari Jawatan PPT (Post, Telegraph dan Telephone).

Mencermati perubahan zaman, dapat dilihat dari sektor pos dan komunikasi mengalami perkembangan secara cepat, saat tahun 1965 berubah melahirkan PN Pos dan Giro, tahun 1978 
berganti jadi Perusahaan Umum Pos dan Giro yang pada saat itu dikukuhkan jadi salah satu badan usaha tunggal dalam penyelenggaraan Dinas Pos dan Giro Pos baik untuk hubungan dalam maupun luar negeri selama 17 tahun dengan status Perum, kemudian saat Juni 1995 mengalami perubahan menjadi Perseroan Terbatas bernama PT. Pos. Sejalan dengan berkembangnya teknologi jejaring, komunikasi, serta informasi. Pos Indonesia telah memiliki sekitar 3.800 Kantor pos online dan didukung dengan mobile pos elektronik di beberapa kota besar. Setiap titik adalah kode pos yang dibuat untuk memudahkan dalam pengelolaan kiriman post yang setiap daerah indonesia dapat dikenali dengan akurat. Sistem kode pos diciptakan untuk memudahkan dalam pengolahan kiriman post dimana setiap jengkal daerah di Indonesia dapat diidentifikasi dengan akurat.

Pos Giro Mobile (PGM) merupakan salah satu aplikasi Android yang diciptakan guna memudahkan akses pelanggan kantor pos terhadap pelayanan transaksi keuangan, termasuk memperkenalkan layanan mobile agar dapat dijalankan dimanapun dan kapanpun. Dengan berkembangnya teknologi informasi serta adanya kebutuhan masyarakat (terkhususnya pada konsumen Kantor pos) akan kemudahan dalam mengakses layanan pos, dimanapun dan kapanpun, serta cara mendukung strategi nasional dalam peningkatan Inklusi keuangan di Indonesia.

PGM juga merupakan layanan yang lebih fleksible dan dapat diintegrasikan dengan bank, merchant dan pihak-pihak yang lain, sehingga dengan memiliki rekening Giro, pelanggan dapat melakukan banyak hal seperti transfer bank, pembayaran dan juga di masa depan pelanggan bisa belanja di Indomaret dengan menggunakan rekening Giro. Pos Giro Mobile juga bisa dikatakan sebagai platform digital berbasis rekening giro pos, yang diberikan untuk yang memiliki rekening giro pos. Pemilik rekening bisa mengakses layanan Giro Pos dan layanan transaksi keuangan pos lainnya secara mobile.

Ihwan Sutardiyanta mengatakan PGM merupakan jawaban mengenai kebutuhan masyarakat yang berubah dengan cepat. Kantor Pos menawarkan kemudahan layanan dan fasilitas layanan transaksi keuangan secara mobile yang dapat diakses kapan saja dan dimana saja. Pelanggan juga dapat memanfaatkan virtual account untuk membayar uang sekolah dan lain-lain. Sehingga dengan adanya aplikasi Pos Giro Mobile (PGM) dapat memberikan kemudahan kepada setiap masyarakat untuk berhubungan dengan Kantor pos atau yang lainnya. Dengan adanya Aplikasi PGM ini masyarakat juga lebih memudahkan masyarakat dalam menyelesaikan segala transaksi yang berhubungan dengan kantor pos. Aplikasi PGM ini memiliki banyak fitur yang bisa dipakai oleh para pengguna yaitu ada Giro Pos, Tagihan PLN Token, BPJS, Telco dan masih banyak lagi. Jadi, aplikasi PGM ini tidak hanya dapat digunakan untuk kantor pos saja tetapi juga bisa digunakan untuk hal lainnya.

PT. Pos Indonesia Padangsidimpuan telah melakukan beberapa cara pada saat pengenalan aplikasi PGM ini kepada masyarakat Padangsidimpuan, yang antara lain:

a. Pengenalan Produk Kepada Masyarakat

PT. Pos Indonesia Padangsidimpuan memperkenalkan produk Pos Giro Mobile dengan mengadakan sosialisasi dengan berbagai mitra - mitra Pos Indonesia Padangsidimpuan di ke berbagai daerah. PT. Pos Indonesia memperkenalkan produk tersebut dengan menjelaskan bahwa aplikasi PGM merupakan aplikasi Smartphone berbasis Android yang diberikan kepada pelanggan sebagai saluran digital untuk mengakses layanan Pos Giro dan layanan transaksi keuangan lainnya secara mandiri. Pos Giro Mobile merupakan aplikasi yang dapat di unduh pada handphone untuk memudahkan masyarakat dalam melakukan transaksi. Selain itu PT. Pos Padangsidimpuan juga menjelaskan keunggulan dari aplikasi Pos Giro Mobile yaitu memiliki berbagai layanan yang dapat di akses melalui aplikasi PGM diantaranya pembayaran berbagai tagihan seperti listrik, PDAM, BPJS dan lainnya. Kemudian, akomodasi pengiriman uang antar rekening Giro pos dan layanan Wesel pos Instan bagi pemegang rekening Giro pos. PT. Pos Padangsidimpuan juga memberikan promo-promo untuk menarik perhatian pengguna baru. Dalam hal ini pos Indonesia meningkatkan kemampuan konsumen untuk mengunduh serta memanfaatkan aplikasi Pos Giro Mobile. 
Dan tidak lupa bahwa Kantor Pos Indonesia memperkenalkan Program customer reward kepada konsumen. Customer reward ini merupakan salah satu program resmi Pos Indonesia untuk mengapresiasi pelanggan setia dengan memberikan reward yang diberikan oleh pihak perusahaan pada konsumen supaya konsumen selalu setia menggunakan pelayanan PT. Pos Indonesia.

b. Melakukan Riset

Riset ini dilaksanakan guna untuk mendapatkan informasi yang tepat mengenai target Pos Giro Mobile, yaitu menargetkan para pengguna aplikasi Pos Giro Mobile dimulai dari umur 17 tahun keatas hingga 50 tahun. Aplikasi Pos Giro Mobile ini juga dapat di pakai oleh wanita atau pria. Serta aplikasi Pos Giro Mobile ini dapat di pakai pada HP Smartphone.

Dalam setiap bisnis yang berbasis e-business, yang paling sulit itu adalah dalam hal pemasaran begitu juga dengan pemasaran aplikasi PGM ini, banyak kendala yang ditemui pada saat memasarkan aplikasi ini yang diantaranya:

1. Minimnya pengetahuan masyarakat tentang aplikasi. Aplikasi Pos Giro Mobile ini termasuk aplikasi yang masih baru di telinga masyarakat, jelas hal ini membuat banyak masyarakat belum mengetahui bahkan terkadang mengabaikan produk aplikasi Pos Giro Mobile, sehingga dalam penerapan pemasaran dan penjualan aplikasi baik itu melalui pemasaran langsung ataupun berupa sosialisasi. Ketika masyarakat ditawarkan aplikasi Pos Giro Mobile banyak masyarakat yang langsung menolak tanpa mengetahui dan melihat aplikasi tersebut. Karena hal itulah, ini adalah salah satu kendala yang terkuat pada saat memasarkan aplikasi PGM ini.

2. Kurangnya fokus Sales SDM dalam melaksanakan Pemasaran Salah satu strategi dalam memasarkan aplikasi Pos Giro Mobile adalah dengan mengadakan promo-promo, namun dalam pelaksanaaan promosinya yang berupa iklan, sosialisasi dan lainnya. Kurangnya fokus beberapa SDM atau karyawan menjadi kendala bagi pos Indonesia dalam penerapannya dilapangan, hal ini didasari pada kebanyakan dari mereka sales sdm PT. Pos Indonesia tidak fokus ada saat mempromosikan aplikasi PGM.

Adapun upaya yang dilakukan oleh PT. Pos Indonesia dalam mengatasi hambatan-hambatan dalam melaksanakan pemasaran aplikasi Pos Giro Mobile adalah sebagai berikut:

1. Melakukan promosi-promosi. Dalam rangka memberikan informasi kepada masyarakat tentang aplikasi Pos Giro Mobile ini, PT. Pos Indonesia gencar melakukan promosi baik itu berupa iklan di jejaring sosial media (Instagram, Facebook, dlI), maupun brosur, spanduk, dan pamflet. Selain itu, PT. Pos Indonesia juga banyak melakukan promosi secara langsung kepada masyarakat melalui door-to-door atau sosialisasi yang tidak hanya kepada mitra pos tetapi juga untuk masyarakat umum.

2. Merekrut sales khusus yang lebih handal dan terampil. Untuk mengatasi kurangnya fokus sales dalam melaksanakan strategi pemasaran yang ditempuh oleh PT. Pos Indonesia, maka PT. Pos Indonesia berencana untuk melakukan pengrekrutan sales baru yang lebih handal dan berkualitas khusus mempromosikan aplikasi pos Indonesia terkhususnya aplikasi PGM, dimana rekrutmen ini diharapkan dapat meningkatkan efektifitas penjualan Pos Giro Mobile sehingga target yang dirancang oleh PT. Pos Indonesia dapat berjalan dengan baik, sebaliknya perekrutan tersebut tetap menjadi bagian dari pegawai kotrak tetap PT. Pos Indonesia, tetapi bukan sebagai pegawai tetap utama PT. Pos Indonesia.

\section{KESIMPULAN DAN SARAN}

1. PT. Pos Indonesia Padangsidimpuan melakukan beberapa hal pada saat memperkenalkan aplikasi Pos Giro Mobile (PGM). Ada dua jenis kegiatan yang dilakukan pada saat pengenalan aplikasi Pos Giro Mobile oleh PT. Pos Indoneisa yaitu, pertama pengenalan produk yaitu PT. Pos Indonesia memperkenal aplikasi Pos Giro Mobile dengan mensosialisasikan aplikasi tersebut kepada mitra - mitra PT. Pos Indonesia Padangsidimpuan dan keberbagai daerah. Dan uga 
memperkenalkan program customer reward terhadap pelanggan. Kedua melakukan riset, PT. Pos Indonesia melakukan riset terhadap aplikasi Pos Giro Mobile yang dimana riset ini dilaksanakan guna untuk mengumpulkan informasi yang tepat mengenai target Pos Giro Mobile yakni menargetkan usia untuk pengguna aplikasi Pos Giro Mobile dari umur 17 Tahun keatas hingga 50 tahun, aplikasi Pos Giro Mobile ini dapat digunakan dengan baik oleh wanita maupun pria. Dan aplikasi Pos Giro Mobile ini dapat digunakan pada HP Smartphone.

2. Kendala yang dihadapi PT. Pos Indonesia Padangsidimpuan dalam memasarkan Pos Giro Mobile (PGM) antara lain adalah kurang fokusnya sales SDM dalam melakukan pemasaran dan penjualan, didukung oleh kurangnya pengetahuan masyarakat terhadap aplikasi Pos Giro Mobile dan minimnya pengetahuan masyarakat tentang IPTEK.

3. Adapun upaya-upaya yang dilakukan PT. Pos Indonesia dalam mengatasi kendala-kendala yang ada pada saat melaksanakan strategi pemasaran Pos Giro Mobile sebagai berikut, melakukan promosi dan sosialisasi kepada masyarakat mengenai manfaat yang didapatkan dalam penggunaan Pos Giro Mobile, serta menjelaskan kegunaan Pos Giro Mobile, dan juga merekrut sales baru yang lebih berkualitas yang memang memiliki skill.

\section{DAFTAR PUSTAKA}

Hasibuan, A. (2020). E-Business: Implementasi, Strategi dan Inovasi. Medan: Yayasan Kita Menulis. Herman, Y. Kajian Tentang Perkembangan E-Business Terhadap Praktik Bisnis. Jurnal Commit.

Hidayat, A. P. Analisis Kinerja Pengiriman Barang Terhadap Pelayanan E-Commerce PT.Pos Indonesia. Jurnal Tranfortasi Multimoda.

Nuraisyah, T. G. E-Business: The Scope of E-Business Towards the Life of Modern Globalization. Jurnal Manajemen Keuangan Syariah.

Permanasari, Y. W. Proses Tranformasi PT.Pos Indonesia (Studi Kasus Pada Kantor Pricessing Centre Semarang). Diponegoro Journal of Management.

Romindo. (2019). E-Commerce Implem (Herman)entasi, Strategi dan Inovasinya. Medan: Yayasan Kita Menulis.

Sari, R. Kualitas Pelayanan PT.Pos Indonesia Cabang Bariton Selatan. Jurnal Administrasi Publik.

Sudarso, A. (2020). Konsep E-Business. Medan: Yayasan Kita Menulis.

Sumarna, D. L. Pengukuran dan Perbaikan Kualitas Pelayanan PT.Pos Indonesia Menggunakan Metode Importance Performance Analysis (IPA). Jurnal Logistik Bisnis.

Wijaya, D. R. Strategi dan Kebijakan Pengembangan E-Business di Indonesia. Jurnal Digital Information \& System Conference. 